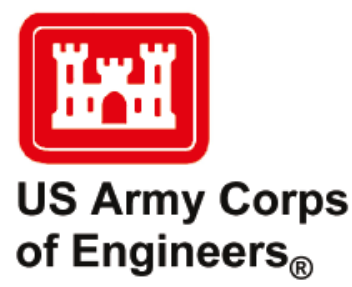

\title{
AIS Data Case Study: Selecting Design Vessels for New Jersey Back Bays Storm Surge Barriers Study
}

by Marin M. Kress and Samuel Weintraub

PURPOSE: The purpose of this Coastal and Hydraulics Engineering technical note (CHETN) is to describe how historic Automatic Identification System (AIS) vessel position data were used to identify a design vessel for use in a storm surge barrier design study. Specifically, this CHETN describes how the AIS data were accessed, how the universe of vessel data was refined to allow for design vessel selection, and how that selection was used in a storm surge barrier (SSB) study. This CHETN draws upon the New Jersey Back Bays Coastal Storm Risk Management Feasibility Study (USACE-NAP 2019), specifically the Appendix B.2 Engineering Appendix Civil document ${ }^{1}$. The New Jersey Back Bays Study itself builds upon the work of the North Atlantic Coast Comprehensive Study (NACCS) initiated after Hurricane Sandy in 2012 (USACE 2015a).

INTRODUCTION: The extent and severity of damage from Hurricane Sandy (aka Superstorm Sandy) in 2012 led to a study of the flood risks to coastal communities within the U.S. Army Corps of Engineers (USACE), North Atlantic Division, stretching from Maine to the coast of Virginia. The resulting NACCS identified the New Jersey Backs Bays (NJBB) as a focus area for study and exploration of flood risk reduction strategies (USACE 2015b). One flood risk reduction option that has been studied since the 2015 publication of the NACCS is SSB across coastal inlet mouths. SSBs are defined as "a series of movable gates that are normally open to let flow pass but will close when storm surge exceeds a certain water level" (USACE 2015b). These SSBs would require openings large enough to accommodate vessel navigation traffic as part of their design considerations. Therefore, potential SSB designs needed information on vessel dimensions for existing vessels that utilize coastal inlets. Identifying the vessel dimensions of local traffic has historically been a laborious endeavor normally involving field observations, finding and calling local vessel operators to ask them about their vessel dimensions, or other methods. However, now most commercial vessels, and many recreational vessels, carry AIS transponder units that can be programmed to broadcast many pieces of information about a vessel, including dimensions along with time-stamped and geo-referenced position reports. As of 2016, AIS carriage requirements set by the U.S. Coast Guard had expanded to include most commercial self-propelled vessels on U.S. navigable waters including any vessel over $65 \mathrm{ft}^{2}$ in length, towing vessels over $26 \mathrm{ft}$ in length with a greater than $600 \mathrm{hp}$ engine, vessels certified to carry 150 or more passengers, dredges in or near a commercial channel, and vessels moving certain dangerous cargo (USCG 2018; US Code of Regulations 2019). Larger vessels are of special interest in SSB study design because they might have limited maneuverability and specific clearance requirements. Additional information about AIS technical standards and history can be found through

\footnotetext{
${ }^{1}$ USACE-NAP (U.S. Army Corps of Engineers, Philadelphia District). In preparation. New Jersey Back Bays Coastal Storm Risk Management Feasibility Study: Appendix B.2: Engineering Appendix Civil. Philadelphia, PA. (Information and published materials from this study are available at https://www.nap.usace.armv.mil/Missions/Civil-Works/New-Jersev-Back-Bavs-Studv/).

${ }^{2}$ For a full list of the spelled-out forms of the units of measure used in this document, please refer to US Government Publishing Office Style Manual, 31st ed. (Washington, DC: US Government Publishing Office, 2016), 248-52,

https://www.govinfo.gov/content/pkg/GPO-STYLEMANUAL-2016/pdf/GPO-STYLEMANUAL-2016.pdf
} 
international groups involved in setting technical standards (IALA 2008; IEC 2001; ITU-R 2014; PIANC 2019). Previous studies have described additional AIS data applications for waterway analysis and planning, which may be relevant to the reader (Mitchell and Scully 2014; Scully and Mitchell 2015; Scully and Mitchell 2017; Tabbert et al. 2020; and Kress et al. 2020).

METHOD: The method described in this CHETN includes the process of acquiring and evaluating AIS data and a summary of the results as part of a larger storm surge barrier study undertaken by USACE Philadelphia District for Great Egg Harbor Inlet, Absecon Inlet, Barnegat Inlet, and Manasquan Inlet, New Jersey (Figure 1). Complete details of those findings and their relation to potential SSB design evaluation will be released through the New Jersey Back Bays Coastal Storm Risk Management Feasibility Study, Appendix B.2 Engineering Appendix Civil ${ }^{1}$.

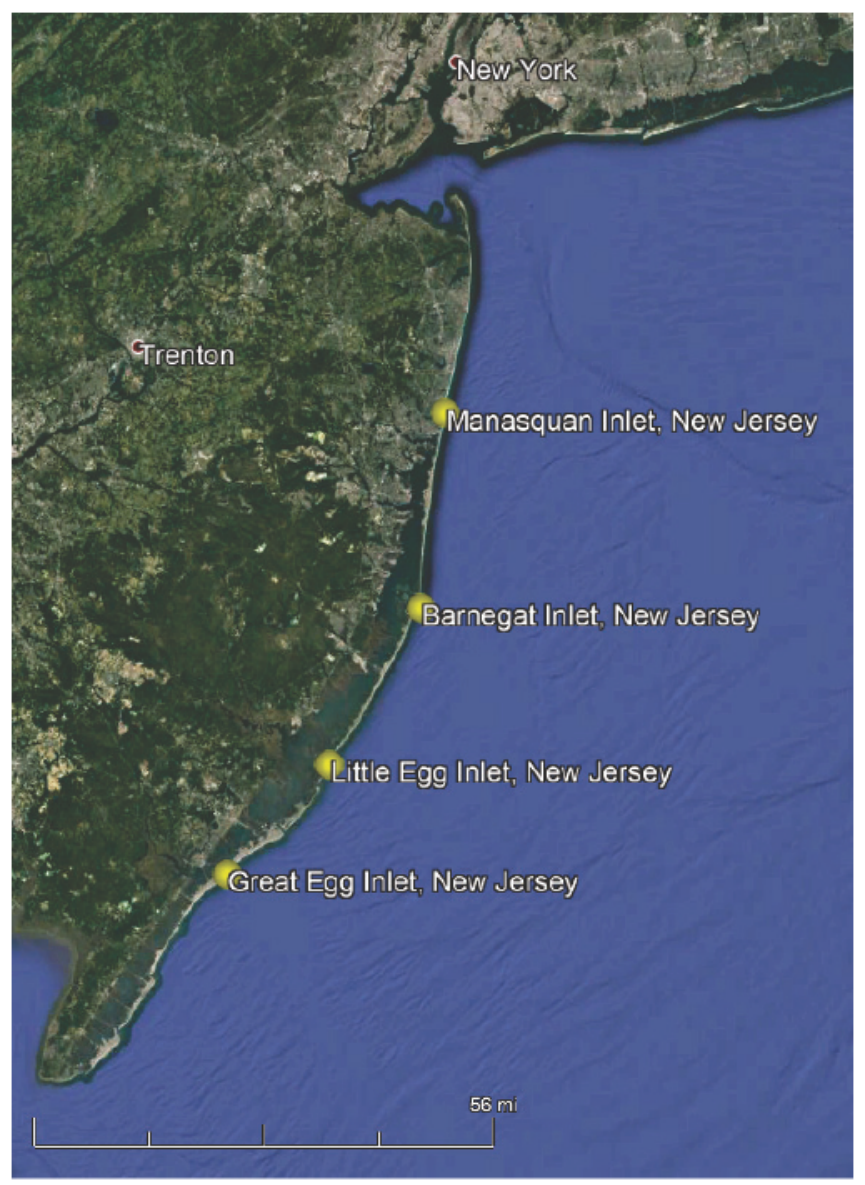

Figure 1. Map of New Jersey Inlets included in study (Manasquan Inlet; Barnegat Inlet; Little Egg Inlet; Great Egg Inlet).

The first step in acquiring AIS data for the four selected study locations was to investigate the availability of AIS data from the U.S. Coast Guard (USCG) Nationwide AIS (NAIS) archive for the locations and time period of interest. Because vessel traffic is assumed to be highest during the summer months, a date range of June 1, 2018, to September 30, 2018 (121 days), was selected as the study period. After the availability of these data was confirmed, separate data queries were sent to the USCG NAIS archive through the AIS Analysis Package (AISAP) web-based software (http://aisportal.usace.army.mil/) (USACE-ERDC 2018). Two types of queries were sent, one for a 365-day period that included the 121-day study duration requesting data at a $5 \mathrm{~min}$ sampling interval and 
another during the July 4 holiday (July $4-8,2018)$ at a $30 \mathrm{sec}$ sampling interval. Sampling intervals determine how many vessel position reports in the area will be retrieved from the NAIS archive. A single $24 \mathrm{hr}$ period queried at a 5 min interval will return a maximum of 288 records per vessel, but a $24 \mathrm{hr}$ period queried at a $30 \mathrm{sec}$ interval will return up to 2,880 records per vessel. Higher sampling rates allow for higher fidelity reconstructions of vessel traffic paths, but the larger files take more time to query and then process.

After receiving historic vessel position report data from the NAIS, the next step was to evaluate the data by examining vessel positions, vessel signal density maps, and vessel dimension data generated from the returned position reports. Vessel signal density maps (heatmaps) display relative signal density, which can reveal where the sampled population of vessels spend time. These hot-spot areas often show up where vessels are moored or moving slower because of navigational or safe operating principles (e.g., constricted channel dimensions, turning actions, or high traffic density). Figure 3 shows an example signal density map from Barnegat Inlet, New Jersey, using AIS data from July 1 to September 30,2018, collected at a 5 min sampling rate. Warmer colors (e.g., yellow and white) represent areas with relatively high signal density, and cooler colors (e.g., blue) represent areas with relatively low signal density. Figure 4 shows the vessel position reports from the same time period. Both the heatmap image and the position report image indicate that the signal density is highest at the marinas where vessels are either moored or moving slowly, thereby recording more signals. As shown in Figure 3, once away from marinas, many vessels spent time in the back-bay area (notably along the peninsula with a sandy beach); this is typical of recreational vessels. When transiting through Barnegat Inlet, vessels primarily use the north side of the inlet, which follows the existing federal navigation channel. Boundaries of the existing federal navigation channel are shown in Figure 2. Similar images of historical vessel activity for each study inlet are included in the New Jersey Back Bays Coastal Storm Risk Management Feasibility Study, Appendix B.2 Engineering Appendix Civil . ${ }^{1}$

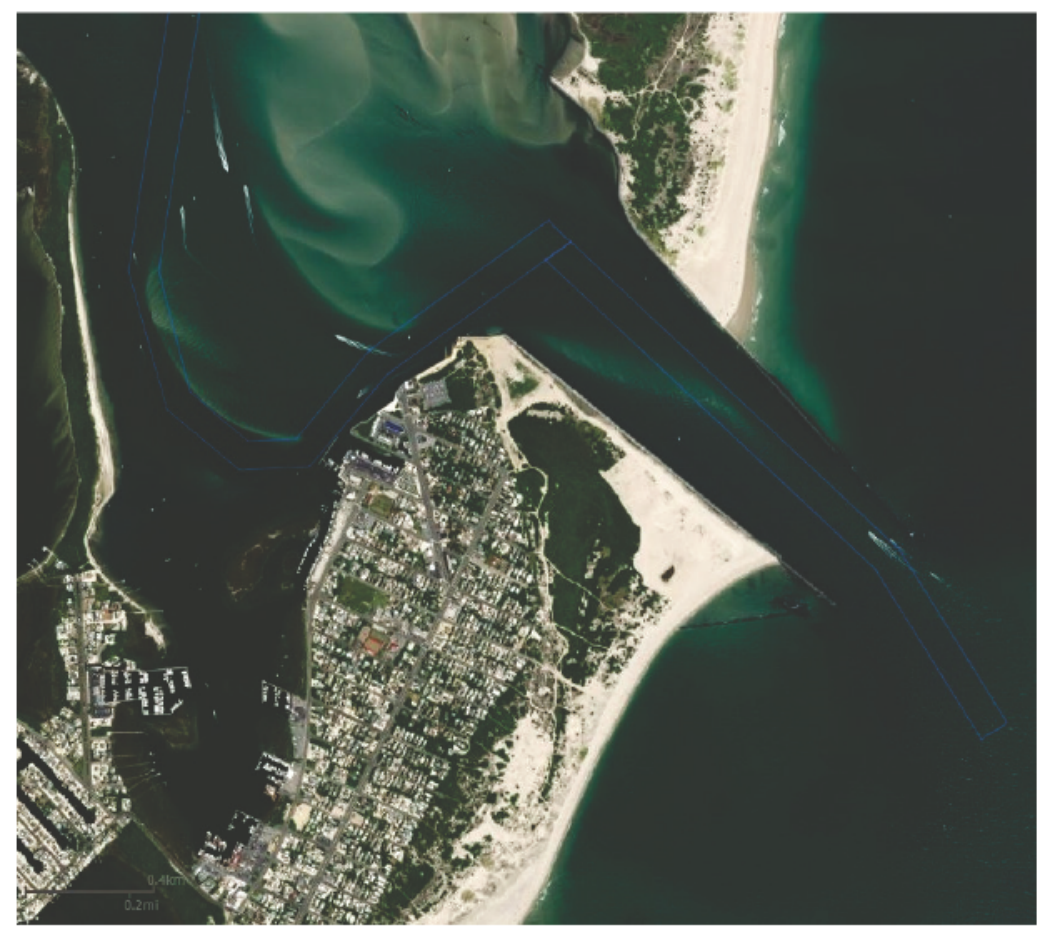

Figure 2. Barnegat Inlet, New Jersey area, with federal navigation channel boundaries shown as blue polygon outlines. 


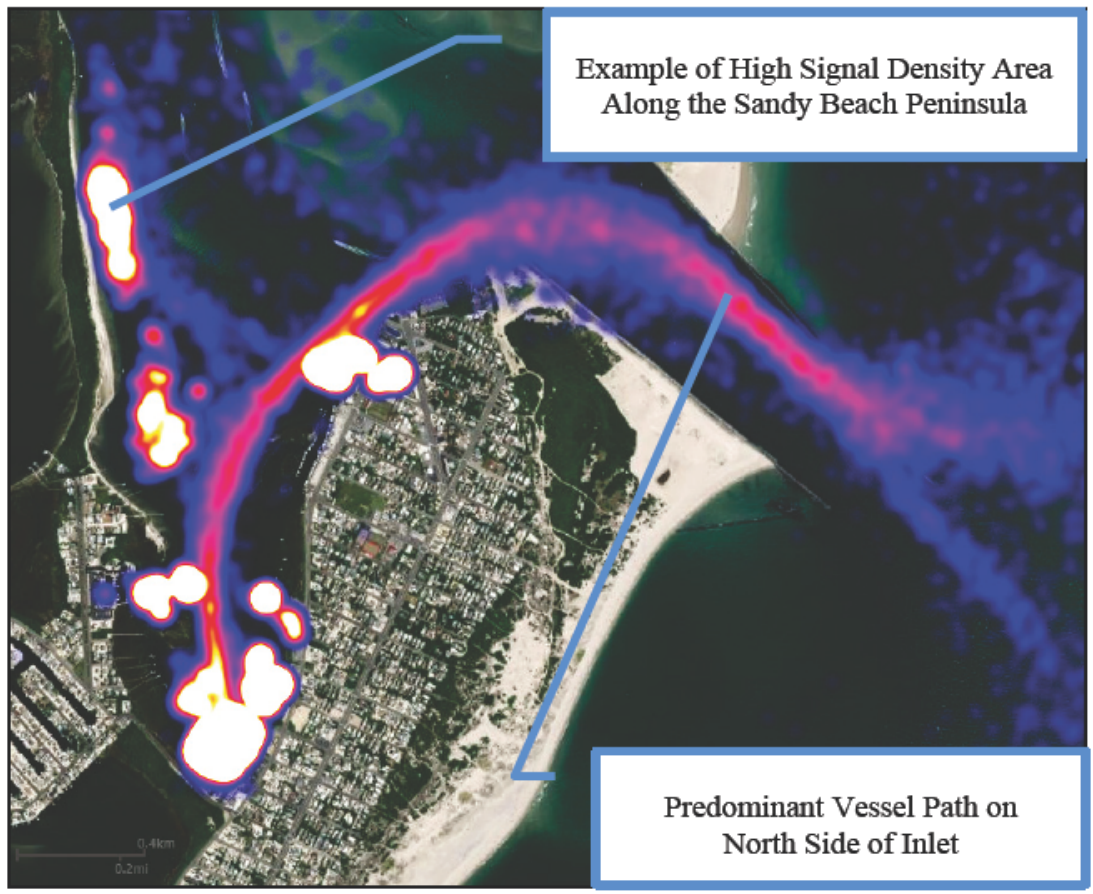

Figure 3. AIS signal density map (heatmap) of vessel position reports in Barnegat Inlet, New Jersey, from July 1 to September 30, 2018, using a 5 min position sampling rate. Created using data from the USCG NAIS processed in AISAP software.

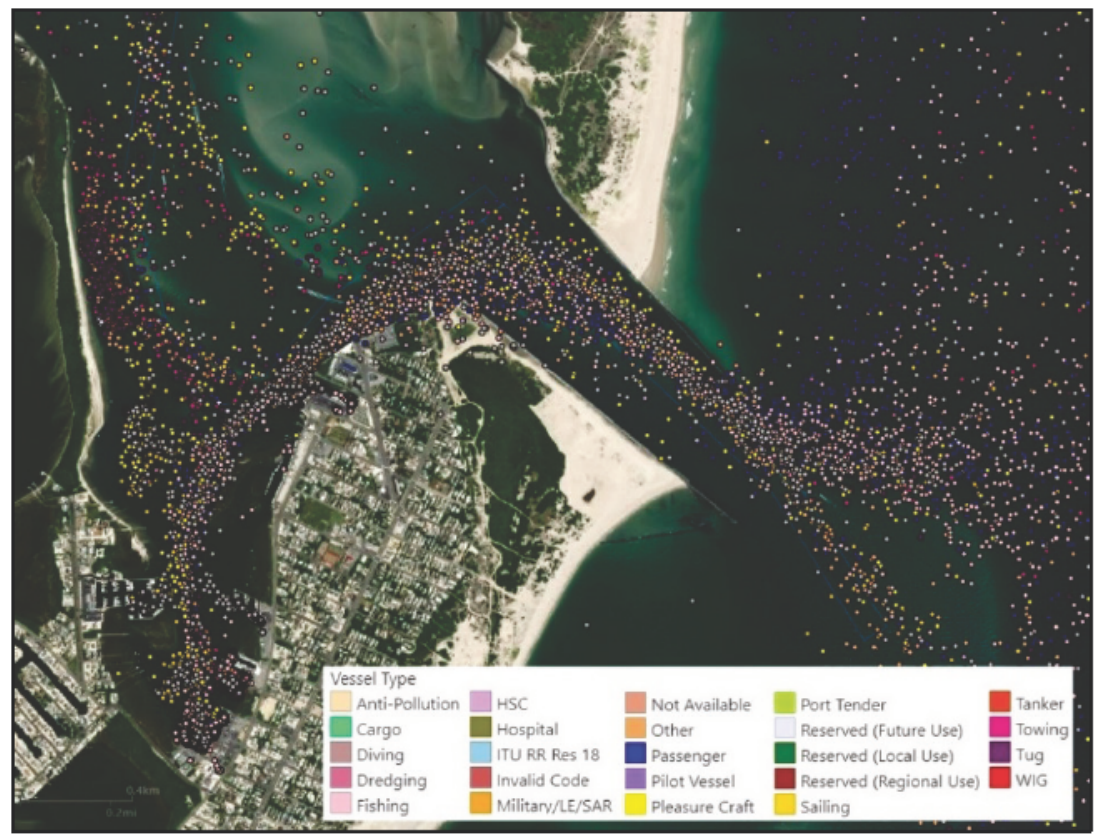

Figure 4. AIS vessel position reports color coded by vessel type in Barnegat Inlet, New Jersey, from July 1 to September 30, 2018 , using a 5 min position sampling rate. Created using data from the USCG NAIS processed in AISAP software. 
Vessel characteristics transmitted as part of the AIS ship static- and voyage-related data message include the draft, length, and width (beam); these are manually programmed into the AIS transceiver by the vessel operator and are generally expected to represent the design dimensions for a vessel; they do not change while a vessel is underway. Note that AIS data fields, which are manually input by the vessel operator, are subject to human error and may be incorrect, missing information, or out of date (Harati-Mokhtari et al. 2007; Robards et al. 2016). For the SSB study, it was important to get vessel width (beam) because this is a critical measurement in setting safe lateral clearance for one-way or two-way traffic through a confined space. Due to the existing bathymetry at proposed SSB locations, vessel draft was not a concern in sizing navigation gates. For each of the study areas, a distribution of reported vessel beam measurements was gathered from AIS data; an example of this distribution from Barnegat Inlet, NJ, is shown in Figure 5.

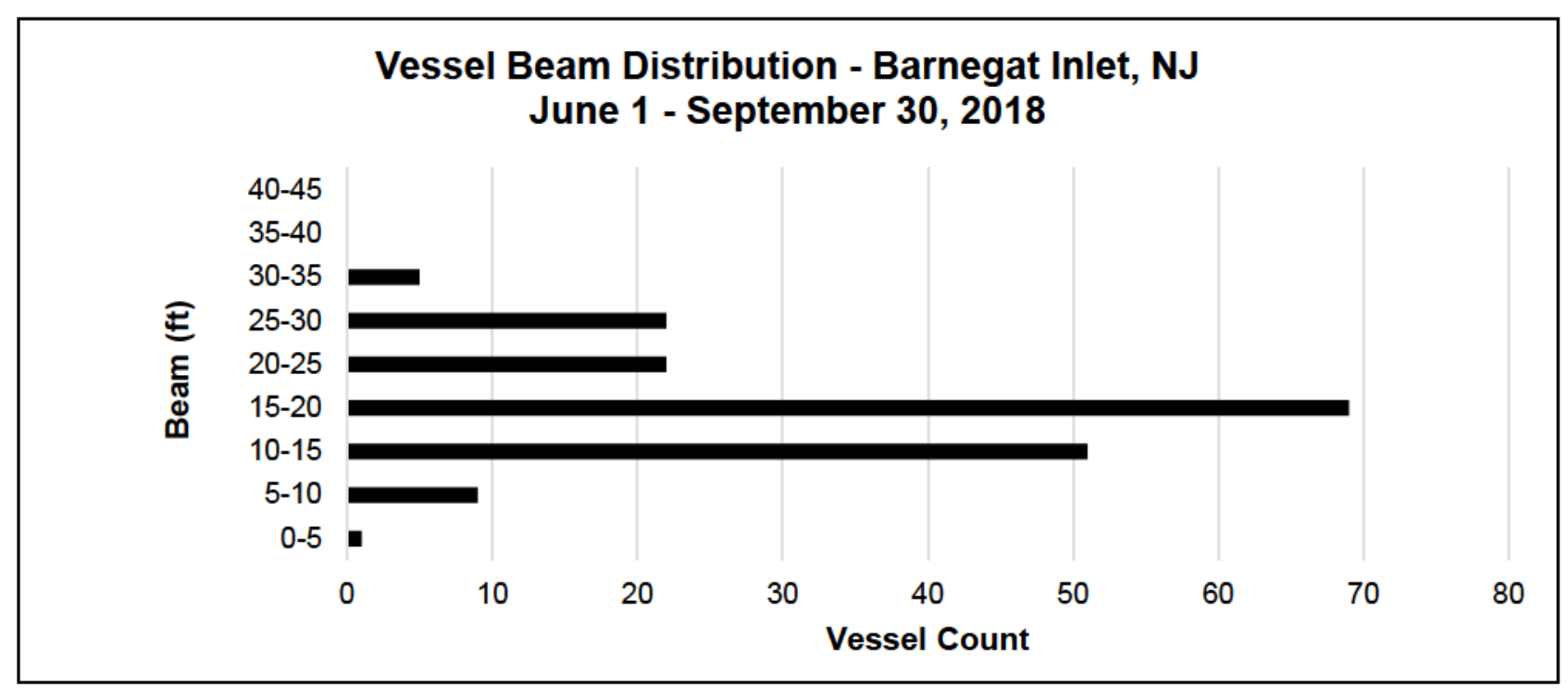

Figure 5. Vessel beam distribution reported in AIS messages from vessels around Barnegat Inlet, New Jersey, from June 1 to September 30, 2018. Redrawn from "Figure 3-25: Vessel Beam - Barnegat Inlet," in New Jersey Back Bays Coastal Storm Risk Management Feasibility Study, Appendix B.2 Engineering Appendix Civil ${ }^{1}$.

At Barnegat Inlet, most observed vessels reported their vessel beam as between 15 to $20 \mathrm{ft}$; however, there were vessels with reported beam in the 30 to $35 \mathrm{ft}$ range. Note that AIS position reports from winter months were compared to position reports from summer months at Great Egg Harbor Inlet and the largest vessels were observed transiting the inlet during summer months, supporting the decision to use summer months as a representative study period ${ }^{1}$. Figure 6 shows the distribution of vessel types as reported in AIS messages, this field is selected by the vessel operator when programming the AIS unit, the majority of vessels transiting the Barnegat Inlet, New Jersey, with data displayed in Figure 6 were pleasure craft (recreational) and fishing type vessels. 


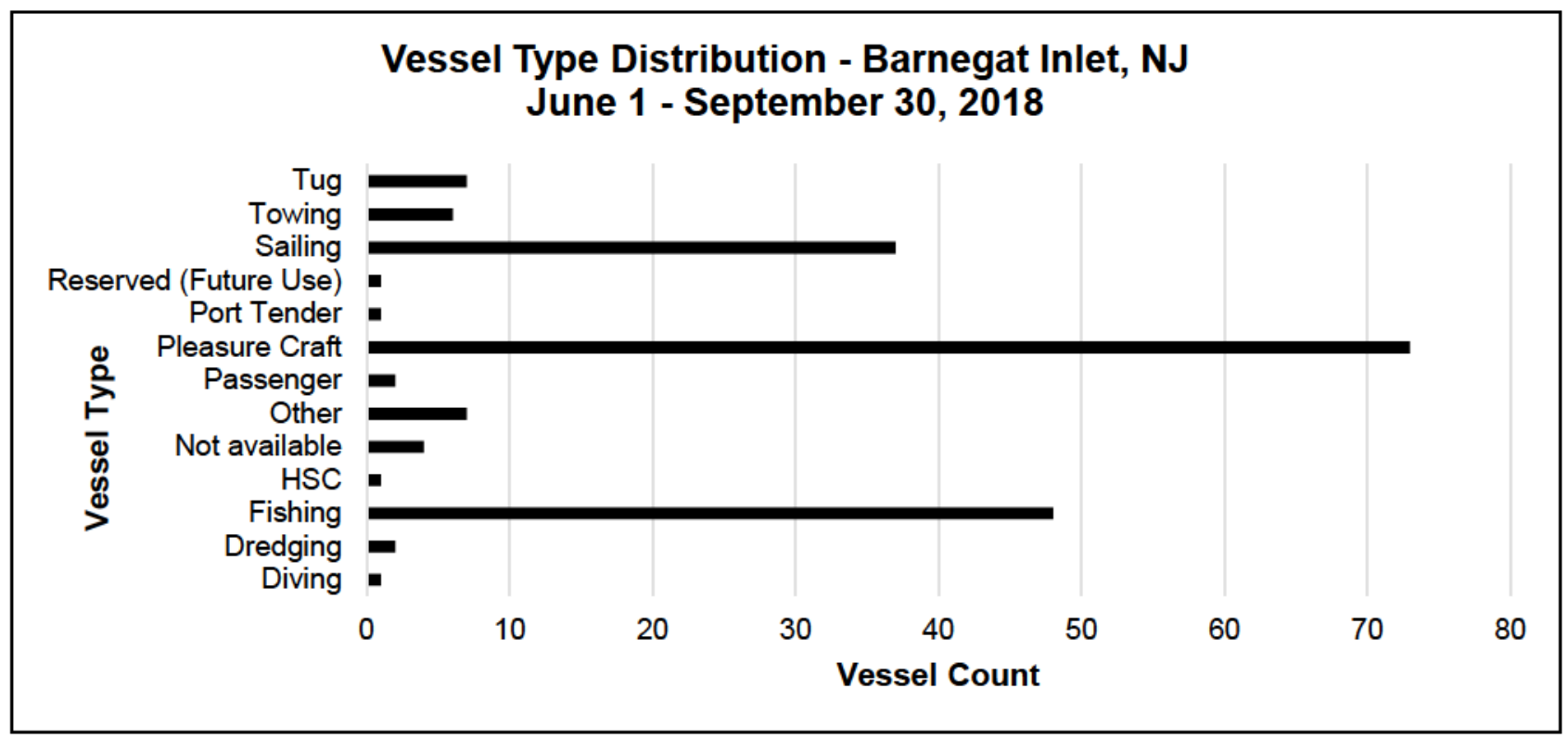

Figure 6. Vessel type distribution reported in AIS messages from vessels around Barnegat Inlet, New Jersey, from June 1 to September 30, 2018. Redrawn from "Figure 3-23: Vessel Type - Barnegat Inlet," in New Jersey Back Bays Coastal Storm Risk Management Feasibility Study, Appendix B.2 Engineering Appendix Civil ${ }^{1}$.

RESULTS: The information about vessel beam distribution for traffic utilizing each of the four inlets, along with other vessel dimensions, was incorporated into suggested measurements for the minimum size of a main navigation opening and a secondary navigation opening at each potential SSB. The current SSB design assumes a combination of sector gates and vertical lift gates. The main navigation openings are currently assumed to be sector gates. Secondary navigation gates may be added into the design to support the smaller recreational vessels and alleviate potential traffic through the main navigation gate. Further analysis is needed to determine the need, location, and gate type for secondary navigation. Although there are vertical clearance restrictions to vertical lift gates, they can be designed to support recreational navigation. The current vertical lift gate design in the NJBB focused array of alternatives provides a $150 \mathrm{ft}$ opening and may need to be increased in size to support secondary navigation. An additional sector gate could also be designed to support secondary navigation, which results in unlimited vertical clearance. There is no singular authoritative design guidance for navigation gates in storm surge barriers, so two references were consulted when calculating the minimum suggested gate opening widths ${ }^{1}$. The two references consulted for calculation guidance were the USACE Engineering Manual 1110-2-1613 Hydraulic Design of DeepDraft Navigation Projects (USACE 2006) and the World Association for Waterborne Transport Infrastructure_Report No. 121 Harbour Approach Channels Design Guidelines (PIANC 2014). ${ }^{1}$ The results of these suggested minimum opening dimensions for potential SSBs along the four study inlets in New Jersey are summarized below in Table 1. The main navigation minimum opening recommendation was informed by the largest vessel dimensions reported through AIS position reports at each inlet, which included two ferries, a fishing boat, and a military vessel. The majority of the vessels reported through the four study inlets were smaller recreational vessels (pleasure crafts), so recommendations for sizing secondary navigation gates were based on these more common recreational vessel dimensions ${ }^{1}$. Vessel dimensions are not the only factor in determining appropriate navigation gate dimensions; hydrodynamic factors such as flow velocity, sediment scour, and potential habitat impacts may also inform suggested gate sizes. 


\begin{tabular}{|c|c|c|c|c|}
\hline \multicolumn{2}{|c|}{ Table 1. Maritime vessel analysis preliminary findings summary*. } \\
\hline $\begin{array}{c}\text { New Jersey Study } \\
\text { Locations }\end{array}$ & $\begin{array}{c}\text { Main } \\
\text { Navigation } \\
\text { Design Vessel } \\
\text { Beam (ft) }\end{array}$ & $\begin{array}{c}\text { Main } \\
\text { Navigation } \\
\text { Minimum } \\
\text { Opening (ft) }\end{array}$ & $\begin{array}{c}\text { Secondary } \\
\text { Navigation } \\
\text { Design Vessel } \\
\text { Beam (ft) }\end{array}$ & $\begin{array}{c}\text { Secondary } \\
\text { Navigation } \\
\text { Minimum } \\
\text { Opening (ft) }\end{array}$ \\
\hline Great Egg Harbor Inlet & 39 & 312 & 13 & 104 \\
\hline Absecon Inlet & 43 & 344 & 20 & 160 \\
\hline Barnegat Inlet & 33 & 264 & 20 & 160 \\
\hline Manasquan Inlet & 39 & 312 & N/A & N/A \\
\hline
\end{tabular}

"Reproduced from "Table 3-7: Maritime Vessel Analysis Summary" in New Jersey Back Bays Coastal Storm Risk Management Feasibility Study, Appendix B.2 Engineering Appendix Civil ${ }^{1}$.

For Absecon Inlet, Barnegat Inlet, and Manasquan Inlet, the main navigation gate is located across an authorized federal navigation channel. At the current phase of the study, it is assumed that the navigation gates must, at a minimum, be sized to allow access through the entire authorized channel width, outside of significant storm events. One of the goals of this AIS analysis was to determine if observed vessels and vessel traffic patterns warranted gate widths larger than the authorized channels. The minimum gate dimensions in Table 1 were all smaller than the authorized channel widths. For that reason, the main navigation gate design suggestions were sized based on the authorized navigation channels, and the AIS data provided additional confidence in the decision to use authorized channel widths.

This CHETN summarizes an example of an engineering study quickly accessing and using recent historical data to make preliminary design recommendations for potential coastal structures that would intersect with federal navigation projects. Recent historical data related to vessel utilization of waterways were available through the USCG NAIS archive, which can be accessed through the webbased AISAP software. These data are available for most U.S. coastal and inland waters and includes most commercial vessels, along with an increasing number of non-commercial recreational vessels.

ADDITIONAL INFORMATION: This CHETN was prepared by Marin Kress, Marin.M.Kress@usace.army.mil, U.S. Army Engineer Research and Development Center (ORCiD https://orcid.org/0000-0002-5835-5686). Sincere appreciation is expressed to the AISAP software team, the USCG NAIS program, and reviewers within Philadelphia District. In-person training on the AISAP software for staff in USACE Philadelphia District during Fiscal Year 19 was funded by the Navigation Systems Research Program. In addition, the authors thank Brandon Scully and Brian Tetreault for insightful comments on this document. The study is funded by the USACE Navigation Systems Research Program. This CHETN should be cited as follows:

Kress, Marin M., and Samuel Weintraub. 2021. AIS Data Case Study: Selecting Design Vessels for New Jersey Back Bays Storm Surge Barriers Study. ERDC/CHL CHETN-IX-54. Vicksburg, MS: U.S. Army Engineer Research and Development Center. http://dx.doi.org/10.21079/11681/39779

\section{REFERENCES}

Harati-Mokhtari, A., A. Wall, P. Brooks, and J. Wang. 2007. “Automatic Identification System (AIS): Data Reliability and Human Error Implications.” Journal of Navigation 60(3): 373-389. https://doi.org/10.1017/S0373463307004298 
IALA (International Association of Marine Aids to Navigation and Lighthouse Authorities). 2008. Establishment of AIS as an Aid to Navigation: Report ID 1062. https://www.iala-aism.org/product/establishment-of-ais-as-an-aid-tonavigation-10621

IEC (International Electrotechnical Commission). 2001. 2001-12 Maritime Navigation and Radiocommunication Equipment and Systems - Automatic Identification Systems (AIS) - Part 2: Class A Shipborne Equipment of the Universal Automatic Identification System (AIS) - Operational and Performance Requirements, Methods of Test and Required Test Results. EC 61993-2. https://www.iec.ch/index.htm

ITU-R (International Telecommunications Union - Radiocommunication Sector). 2014. Recommendation ITU-R M.1371: Technical Characteristics for an Automatic Identification System Using Time Division Multiple Access in the VHF Maritime Mobile Frequency Band. https://www.itu.int/rec/R-REC-M.1371/en

Kress, M. M., B. J. Tetreault, K. N. Mitchell, M. Balazik, and M. C. Booton 2020. AIS Data: Real-Time Operation Support, Incident Investigations, and Waterway Use Analysis. ERDC/CHL CHETN-IX-53. Vicksburg, MS: U.S. Army Engineer Research and Development Center. $\underline{\text { http://dx.doi.org/10.21079/11681/36395 }}$

Mitchell, K. N., and B. N. Scully. 2014. "Waterway Performance Monitoring via Automatic Identification System (AIS) Data." Transportation Research Record: Journal of Transportation 2426 (1): 20-26. https://doi.org/10.3141/2426$\underline{03}$

PIANC (The World Association for Waterborne Transport Infrastructure). 2019. Guidelines and Recommendations for River Information Services. InCom Working Group Report Number 125/I-2019. https://www.pianc.org/publications/inlandnavigation-commission/wg125-1

PIANC. 2014. Harbour Approach Channels Design Guidelines. MarCom Working Group Report No. 121-2014. https://www.pianc.org/publications/marcom/harbour-approach-channels-design-guidelines

Robards, M. D., G. K. Silber, J. D. Adams, J. Arroyo, D. Lorenzini, K. Schwehr, and J. Amos. 2016. "Conservation Science and Policy Applications of the Marine Vessel Automatic Identification System (AIS) - A Review." Bulletin of Marine Science 92(1): 75-103. https://doi.org/10.5343/bms.2015.1034

Scully, B., and K. N. Mitchell. 2015. Archival Automatic Identification System (AIS) Data for Navigation Project Performance Evaluation. ERDC/CHL CHETN-IX-40. Vicksburg, MS: U.S. Army Engineer Research and Development Center. http://hdl.handle.net/11681/2066

Scully, B. M., and K. N. Mitchell. 2017. "Underkeel Clearance Reliability Model for Dredged Navigation Channels." Transportation Research Record: Journal of the Transportation Research Board 2611: 41-49. http://dx.doi.org/10.3141/2611-05

Tabbert, C., J. Vest, A. Rhoads, D. Myers, T. Lauth, E. Brauer, J. Wallace, D. Gordon, and M. Kress. 2020. AIS Data Case Study: St. Louis Area Commercial Vessel Fleeting Activity and Potential River Training Structures. ERDC/CHL CHETN-IX-52. Vicksburg, MS: U.S. Army Engineer Research and Development Center. http://dx.doi.org/10.21079/11681/36334

USACE (U.S. Army Corps of Engineers). 2006. Engineering Manual 1110-2-1613: Hydraulic Design of Deep-Draft Navigation Projects. Washington, DC: U.S. Army Corps of Engineers. https://www.publications.usace.armv.mil/Portals/76/Publications/EngineerMamuals/EM 1110-21613.pdf?ver $=2013-09-04-161111-177$.

USACE. 2015a. North Atlantic Coast Comprehensive Study: Resilient Adaptation to Increasing Risk - Main Report, Final Report. New York, NY. https://www.nad.usace.armv.mil/Portals/40/docs/NACCS/NACCS main report.pdf

USACE. 2015b. North Atlantic Coast Comprehensive Study: Appendix D: State and District of Columbia Analyses: State Chapter D-6: State of New Jersey. New York, NY. https://www.nad.usace.armv.mil/Portals/40/docs/NACCS/Annex_D_Appendices/NACCS_Appendix_D6 New Jerse $\underline{v . p d f}$ 
USACE-ERDC (U.S. Army Corps of Engineers, U.S. Army Engineer Research and Development Center). 2018. AIS Analysis Package (AISAP). Software package. https://ais-portal.usace.armv.mil

USACE-NAP (U.S. Army Corps of Engineers-Philadelphia District). 2019. New Jersey Back Bays Coastal Storm Risk Management Interim Feasibility Study and Environmental Scoping Document: Main Report. Philadelphia, PA. https://www.nap.usace.armv.mil/Portals/39/docs/Civil/NJBB/Interim\%20Report/INJBB_Main_Report_Interim.pdf $\underline{? v e r=2019-02-28-135220-997}$

USCG (U.S. Coast Guard). 2018. Navigation Center: Automatic Identification System Overview. http://www.navcen.uscg.gov/?pageName=AISmain

US Code of Regulations. 2019. Title 33-Navigation and Navigable Waters. "Part 164-Navigation Safety Regulations." 33 C.F.R. § 164.46. Washington, DC. https://www.govinfo.gov/content/pkg/CFR-2019-title33-vol2/xml/CFR-2019title33-vol2-part164.xml

NOTE: The contents of this technical note are not to be used for advertising, publication or promotional purposes. Citation of trade names does not constitute an official 